desirable that labour should be terminated. The cervix felt irregularly dilated, and rather than apply the forceps I preferred to tarn the child, and by means of the breech to effect further dilatation before the passage of the head. I was kindly assisted in the management of this case by the obstetric resident at Guy's, Dr. Mallam (now of Shepherd'sbush), and he placed the patient under the influence of chloroform. I then brought down one foot, and kept the breech bearing steadily on the cervix. Unfortunately a large loop of funis came down, which was very difficult to replace. After some time the breech slipped through the os uteri, and, aided by traction, the shoulders, and then the head. The child was still. No unusual amount of hæmorrhage followed the birth. The patient's condition next day was very favourable, the pulse, twelve hours after labour, being only 80 per minute. Her convalescence from labour was satisfactory, and during that time no marked increase or diminution was noticed in the size of the cervix uteri. Severe pelvic pains and an increased offensive vaginal discharge, however, came on, and on Dec. 11th she was admitted under my eare into Guy's Hospital. She was under observation either as an in-patient or out-patient during the whole of the year 1870 . The disease advanced, the cervix forming a large ulcerating mass, with its lips glued to the vaginal walls. Various local applications were used with a view to arrest the hæmorrhage and check the disease. Bromine was applied on three occasions, but she steadily declined, and died at home in April, 1871, eighteen months after labour.

CASE 2. Cancer of vagina; slight contraction of peluis; induction of labour at eighth month; dilatation by water-pressure; successful result of labour to mother and child.-Harriet W-, aged forty-two, was admitted into Guy's Hospital under Dr. Braxton Hicks on June 25th, 1872, and came under my care for delivery during his absence from town in the month of August. She had been married for twenty years, but had never had a child. Her husband died in the beginning of 1871, and she was married a second time in November of the same jear. She presented herself at the hospital with retention of urine, and great difficulty was experienced in finding the urethra and in passing a catheter. An abdominal tumour was felt extending above the umbilicus. This was at first thought to be the distended bladder, but it was soon found to be the pregnant uterus. The periods had not appeared regularly since the beginning of December. In January she had much soreness about the vagina, great pain and diffeulty in micturition, and a profuse, thick, offensive vaginal discharge. In February, after much difficulty, a catheter was passed into the bladder at one of the hospitals, and kept in for some time. Severe pelvic pain and pain in the back came on subsequently, and occasional retention of urine for two or three days. The whole anterior wall of the vagina was occupied by an indurated mass, having a foul, irregular, ulcerating surface. The vagina was so filled by this, that one finger was with difficulty passed into it, and gave great pain to the patient. The cervix uteri was high up, and not implicated in the disease, but the urethra, even to the meatus, was so much involved that it was a difficult task to follow its course. Dr. Hicks injected some bromine and alcohol in to the growth on July 5th, the patient being under chloroform, but no marked change was produced by it. The external conjugate diameter of the pelvis was 7 inches; the distance between the anterior superior spinous processes, 9 inches; and between the most prominent parts of the crests, $10 \frac{3}{4}$ inches. In the afternoon of the 12th of August-about 250 days from the cessation of the last period - I endeavoured to pass an elastic tube between the membranes and the uterine wall, but failed; manipnlation was so painful that she was placed under the influence of chloroform, and, keeping the cervix steady with two fingers of the left hand, I again tried, but apparently so adherent were the membranes to the riterus all around that I could not succeed in passing the tabe. I then ruptured the membranes. A spherical bag, about two inches in diameter, was introduced into the vagina at 5 o'clock, and then distended by bydrostatic pressure-seren feet of water. The pain complained of was very great. This was partly reliered by a subcutaneous injection of morphia, which was repeated twice or thrice in the course of the night. At 8 o'clock the spherical bag was found to exercise but little pressure on the lower part of the vagina; it was consequently withdrawn, and a Barnes's bag was introduced and distended so as to make direct pressure on this part. At 3.30 A.Mr. the spherical bag was again introduced. Dterine pains were now coming on regularly. By the middle of the day the cervix uteri was fully dilated, the child's head bearing on the vagina. I thought it best now to aid delivery; and Mr.R. J. Pye-Smith having administered chloroform, Mr. F. C. Turner, obstetric resident, applied the long double-curved forceps, and slowly brought down the fotal head, the uterus at the same time acting well. Notwithstanding great care, there was a slight rent in the perineum during the passage of the head. The child had its nails perfect, and its testes in the scrotum. It made but feeble efforts at respiration at first; but it soon revived. The lower part of the posterior vaginal wall and the mar. gins of the perineal wound formed a superficial slough; but with quinine and iron internally, and carbolic oil externally, this soon improved. The temperature on successive days is reported as $99.7^{\circ}, 101.8^{\circ}$, and $100 \cdot 2^{\circ} \mathrm{Fahr}$. the pulse on each of these days 120 . She left the hospital about a month after labour, and has since been an occasional attendant among my out-patients. The disease has been steadily progressing in every direction; but she was alive the beginning of this year.

Finsbury-square.

\section{CASE OF POISONING BY CARBOLIC ACID.}

\section{BY T. H. BRABANT,}

HOUSA-PHYSICTAN, ST. GRORGE'S HOSPITAL.

A CASE of poisoning by carbolic acid has recently occurred in St. George's Hospital, and as such accidents have been of rare occurrence, I think it may be interesting to publish a few short notes of the case.

On Thursday, February 13th, I was called in haste to come and see a patient-a woman aged forty-four, admitted the previous day with bronchitis and emphysema-to whom a nurse had by mistake administered strong carbolic acid instead of a dose of senna. I found the patient sitting up in bed, labouring under great dyspnœa, and apparently suffering acute pain. She was unable to speak, but kept her hands firmly pressed over the region of the sternum, as if to indicate that there was the seat of pain. She was very restless, and groaned continuously. The breath smelt strongly of carbolic acid, the interior of the mouth and lips was charred white, and there was a brown scar on the chin. The pulse was quick (140 in the minute) and feeble. An emetic of sulphate of zinc mixed with olive oil was immediately administered, which she swallowed with great diffculty, and I afterwards endeavoured to get her to drink warm water mixed with oil, but without success, as the power of deglutition became lost. No romiting ensued, and she soon sank into a state of stupor, the breathing became slow and stertorous, and the pulse excessively feeble. Dr. Barclay now saw the patient, and the stomachpump was introduced by the house-surgeon, and warm water injected. She gradually sank, and died comatose fifty minutes after taking the poison. The amount of poison taken was not known at the time, but it was afterwards ascertained to have been nearly a fluid ounce of the impure commercial carbolic acid.

The post-mortem examination was made twenty-eight hours after death. There was a brown stain on the chin extending to the angle of the mouth. Old pleural adhesions existed on both sides. The left lung was greatly congested, the right emphysematous; the broncbial mucous membrane of both was injected, and the tubes full of frothy mucus. The left ventricle of the heart was strongly contracted, the right partly so; the organ was natural. Larynx and trachea natural. The mucous membrane of the mouth, œsophagus, and stomach was converted into a soft white material, giving the organ very much the appearance of being covered with a thin layer of white lead. This easily peeled off, exposing a bright-red surface beneath. These appearances ceased at the pylorus. The stomach was strongly corrugated, and contained about, two ounces of brown fluid smelling powerfully of carbolic acid. There were a few congested patches in the duodenum. The ventricles of the brain contained about an ounce of clear 
fluid; the organ was otherwise natural. All the other viscera were natural. The blood was uniformly fluid, and on exposure became of a bright-red colour. No smell of carbolic acid could be detected in any of the viscera, with the exception of the stomach.

\section{9 altirux}

\section{HOSPITAL PRACTICE, BRITISH AND FOREIGN.}

Nulla autem est alia pro certo noscendi via, nisi quamplurimas et morborum et dissectionum historias, tum aliorum, tum proprias collectas habere, et inter se comparare.-Morgand De Sed. et Caus. Morb., lib.iv. Procmium.

\section{KING'S COLLEGE HOSPITAL.}

PAPILLOMATOUS TUMOUR IN THE FOURTH VENTRICLE OF THE BRAIN.

(Under the care of Dr. Garrod.)

NoTwithsTaNdiNG the great advancement that has been recently made in our knowledge of brain diseases, it must be admitted that the diagnosis of the presence of a cerebral tumour, and more especially its localisation, is often exceedingly uncertain, if not impossible. Bamberger has, indeed, stated that, "with a few exceptions, the diagnosis of tumours of the brain is rather a guess than a diagnosis; and the determination of its locality, likewise with certain exceptions, is impossible." This is, perhaps, saying too much; but it is true to a very considerable extent. A vlear knowledge of the anatomical and physiological relations of the different portions of the brain will often serve to establish a definite diagnosis ; but, on the other hand, it is not at all uncommon to find, after death, a tumour in some portion of the encephalon which, during life, gave rise to no pathognomonic symptom. It will, however, generally be found that the evidence afforded at the autopsy is sufficient to explain the synptoms that were exhibited during life, although these symptoms were not of themselves sufficient to indicate the seat of the growth. It was hoped that the ophthalmoscope would be of great use in the diagnosis of brain affections. This hope has, however, only been partially realised; for although this instrument will often afford valuable evidence of intracranial mischief, it is absolutely valueless as a means for localising the morbid change, and sometimes even affords negative results.

It is interesting to note, in the following case-for the notes of which we are indebted to Mr. J. H. Philpot, M.B., house-physician,- the great irregularity in the respiration and the temperature: the former ranging from 5 to 20 ; and the latter from $96^{\circ}$ to $98.6^{\circ}$ six days before death, and to $107.5^{\circ}$ on the day of decease.

W. R-, aged eleven, a healthy-looking country lad, engaged in farm-work, was admitted into the hospital on December 23rd, 1872. His father stated that the boy had been strong and healthy up to the previous June, when a heavy gate had fallen upon him. From that time it was noticed that his walk had been gradually growing more and more unsteady, and that he was disinclined to ride on horseback. A month after the accident he was obliged to give up work, and remained in-doors, sitting in a fixed attitude and shunning exertion. A fortnight before admirsion the unsteadiness in his gait had increased to such an extent that he was unable to walk without assistance, and had to be carried upstairs to bed. Within the last few days his sight had begun to fail.

On admission the following notes were taken :-The patient is of healthy appearance, tall for his age, but very thin the face is flushed, and has rather a vacant look; pupils widely dilated, a decided internal squint of the right eye. He is unable to walk without aid. On making the attempt his legs are thrown irregularly forwards and outwards, and brought to the ground with a jerk. On closing his eyes his movements are much more irregular; left to himself be staggers and falls. The power of resisting forcible extension of the legs is only slightly diminished; the hands grasp awkwardly, but with normal power.
Sensation is perfect in all parts. His sight is much impaired; he can tell light from darkness, but cannot read the largest type. On ophthalmoscopic examination there is evidence of double optic neuritis. He complains of some pain at the back of the head and neck, intensified by percussion; there is no tenderness down the spine. On being addressed the patient answers sensibly, but generally in monosyllables; he is slow of comprehension. Heart and lung sounds healthy. Pulse 100, regular; respiration slow and sighing. Skin dry and scaly in parts; tache cérébrale well marked. Temperature in axilla $100 \cdot 4^{\circ}$. Urine is passed unconsciously; contains no albumen. Abdomen boat-shaped; bowels much confined. He sleeps badly, takes food badly, but has no diffeulty in swallowing.

He remained in this condition for a week, getting more awkward in his gait, and losing power in both legs and arms. He was occasionally troubled with vomiting. On Dec. 31st he was noticed to be more dull, and he wandered a little during the night. The pulse and respiration were found to be slow and irregular. There was some difficulty in deglutition, fluids returning through the nose. He had become almost entirely helpless. The sight was almost gone. The next day some facial palsy on the right side was noticed. A week later (Jan. 8th, 1873) he had become more unconscious, being roused with difficulty. He was quite blind. The facial palsy and the internal squint on the right side persisted. He was entirely helpless, passing motions and urine unconsciously. The jaws could not be opened to more than half an inch. His pulse varied from 60 to 84 ; the respiration from 5 to 20 : both were irregular. The temperature ranged from $96^{\circ}$ to $98 \cdot 6^{\circ}$.

Jan. 13th, 1873.-The pulse and respiration were quick, and had now become regular. The temperature had risen to $103.7^{\circ}$. He was nearly comatose, and refused food.

4th.- He passed into complete coma, there being entire palsy of motion and sensation. The lips and face were livid, there was some rattling in the throat, and moist râles were heard over the lungs. Pupils contracted. The temperature rose to $107 \cdot 1^{\circ}$, and in the evening to $107.5^{\circ}$. Death took place quietly, and without convulsion, at 7 P.Ir.

At the autopsy, made by Dr. Kelly twenty-five hours after death, the calvaria was found to be very thin, in parts quite translucent. The brain was pale and anæmic, with the convolutions flattened out. There was a considerable amount of clear serous fluid distending the lateral ventricles, the walls of which were quite natural. A tumour was found occupying the fourth ventricle, pushing upwards the velum, and pushing outwards the cerebellum on each side, while it also grew downwards and appeared at the base of the brain on the left side of the medulla. The tumour was tremulous and of irregular shape. Its greatest breadth was at least an inch and a half. The surface was uneven; the colour yellowish and jelly-like, but red in parts where small hæmorrhages had occurred. It was plentifully supplied with vessels. Under the microscope it was seen to be a papilloma, with a delicate network of fibrous tissue, each papilla being covered with columnar epithelium. The other organs of the body were healthy.

The above case is abridged from notes earefully taken by Mr. Homan.

The case requires but little comment. Some of the symptoms were undoubtedly due to the serous effusion into the lateral ventricle, which was probably of a mechanical origin; but the earlier symptoms, the ataxy, the pain, the facial palsy, and the internal squint, are certainly to be attributed to the pressure of the tumour on the surrounding important structures.

\section{CANCER HOSPITAL}

EPITHELIOMA OF THE TONGUE; REMOVAL BY THE WIRE ECRASEUR; RECOVERY.

(Under the care of Mr. HAYWARD.)

Fon the notes of the following case we are indebted to Mr. J. H. Crombie, house-surgeon.

The patient, a male, forty-five years of age, was admitted on July $30 t h, 1872$, suffering from an ulcer, nearly the size of a florin, on the left edge of the dorsum of the tongue. $\mathrm{He}$ had previously been a hard smoker, having been engaged all day in superintending out-door work as a foreman 